STUDI

FRANCESI

\section{Studi Francesi}

Rivista quadrimestrale fondata da Franco Simone

194 (LXV | II) | 2021

Baudelaire et son cénacle

\title{
PETER VON MATT, Sept baisers. Bonheur et malheur en littérature
}

\section{Roberta Sapino}

\section{OpenEdition}

\section{Journals}

\section{Edizione digitale}

URL: https://journals.openedition.org/studifrancesi/45680

DOI: $10.4000 /$ studifrancesi.45680

ISSN: 2421-5856

\section{Editore}

Rosenberg \& Sellier

\section{Edizione cartacea}

Data di pubblicazione: 1 août 2021

Paginazione: 425-426

ISSN: 0039-2944

\section{Notizia bibliografica digitale}

Roberta Sapino, «PETER von matt, Sept baisers. Bonheur et malheur en littérature», Studi Francesi [Online], 194 (LXV | II) | 2021, online dal 01 septembre 2021, consultato il 14 octobre 2022. URL: http:// journals.openedition.org/studifrancesi/45680 ; DOI: https://doi.org/10.4000/studifrancesi.45680

Questo documento è stato generato automaticamente il 14 octobre 2022.

\section{(2) $\Theta \Theta \Theta$}

Creative Commons - Attribuzione - Non commerciale - Non opere derivate 4.0 Internazionale - CC BY NC-ND 4.0

https://creativecommons.org/licenses/by-nc-nd/4.0/ 


\title{
PETER VON MATT, Sept baisers. Bonheur et malheur en littérature
}

\author{
Roberta Sapino
}

\section{NOTIZIA}

PETER VON MATT, Sept baisers. Bonheur et malheur en littérature, trad. L. Felchlin, Paris, Alma, 2019, $302 \mathrm{pp}$.

1 Il dettaglio dell'incontro tra i due volti nel celeberrimo Bacio di Klimt campeggia sulla copertina di questo affascinante volume di PETER VON MATT, edito dapprima in tedesco, nel 2017, presso le edizioni Carl Hanser Verlag di Monaco (Sieben Küsse. Glück und Unglück in der Literatur) e ora reso accessibile al pubblico francofono nella traduzione di Lionel Felchlin.

2 Professore emerito dell'Università di Zurigo, letterato e filologo, membro dell'Accademia tedesca per la lingua e la letteratura, von Matt accompagna il lettore alla scoperta, o alla riscoperta, di storie, scene, narrazioni assumendo una postura in cui all'erudizione e alla riflessione teorica si associa la condivisione del piacere più intimo della lettura, della scoperta, della suggestione.

3 Fulcro del volume è il bacio: non i mille baci e poi cento che implora Catullo (seppur a questi sia dedicata una sezione del capitolo introduttivo, intitolato «La connaissance du bonheur et la question du nombre de baisers», pp. 11-26), ma il bacio singolo - evento eccezionale e irripetibile "qui doit éclipser toute pluralité", rottura dell'equilibrio agognata o inattesa, ma sempre rivelatrice poiché il bacio, osserva l'autore, "puise en profondeur dans la connaissance de soi et des autres".

Oltre all'evidente questione tematica, a fare da fil rouge tra i vari capitoli è la celebrazione della libertà assoluta della letteratura, che vale anche come premessa metodologica. Grazie al valore simbolico che le appartiene, la letteratura ha la capacità di dilatare fino al parossismo un evento apparentemente minuscolo («elle peut faire d'une petite chose un point cardinal et de la tour de Babel un décor en arrière-plan») e 
di ragionare nella forma concreta dell'incontro sempre problematico, individuale, unico tra personaggi. "La littérature pense en scènes» leggiamo in diversi punti del testo: la letteratura non traduce in scene ciò che la filosofia formalizza in teorie, ma procede secondo logiche che le sono proprie e si concretizza in testi portatori di individualità, necessariamente refrattari a modelli critici e teorici troppo rigorosi ( «C'est le problème des études littéraires. Les plus beaux modèles qu'elles développent souffrent de ce que l'individualité de l'œuvre ne s'y fond jamais complètement. Quand elles le savent, les modèles deviennent des truchements de la connaissance, quand elles l'oublient, ils transforment l'œuvre en une construction figée»).

5 I sette baci evocati nel titolo appartengono agli altrettanti romanzi e racconti della letteratura europea e americana su cui von Matt si sofferma nei diversi capitoli: Mrs Dalloway di Virginia Woolf («Le joyau caché», pp. 27-56), Il grande Gatsby di F. Scott Fitzgerald («La danse macabre des Roaring Twenties», pp. 57-78), Sette leggende di Gottfried Keller, che l'autore definisce «l'un des événements en prose les plus exquis en langue allemande de la seconde moitié du XIX siècle» («Un songe de la littérature bourgeoise», pp. 79-103), Il povero suonatore di Franz Grillparzer, che von Matt pone in dialogo con il Bartleby di Herman Melville («Un fol-en-Christ de la musique», pp. 106-162), La marchesa di O...di Heinrich von Kleist («La scène sous la forme d'un monstre», pp. 163-207), Moderato cantabile di Marguerite Duras ("Quand le bonheur et le malheur coïncident», pp. 209-243) e Un bacio di Čechov («Le bonheur comme une infection», pp. 245-275). Ma innumerevoli altre opere e personalità del mondo letterario e artistico entrano nel discorso di von Matt, la cui «osculogie, comme on pourrait appeler la science du baiser» spazia da Marziale a Shakespeare, da Tacito a Ingeborg Bachmann.

6 In ogni sezione, la scena del bacio è il fulcro di una più ampia riflessione sull'esperienza del bonheur e sulla possibilità per l'essere umano di riconoscerla, comprenderla, tradurla in parole nella tensione tra "cliché rhétorique" e "radicalité dangereuse". Alla Clarissa di Virgina Woolf che non teme, facendo eco all'Otello shakespeariano, di trasgredire l'opposizione tra bonheur e morte si affiancano così, per limitarci a pochi esempi, la concezione di bonheur espressa nell'opera di Keller, indissolubilmente legata al pensiero borghese ottocentesco e dipendente tanto dalla "jubilation de l'âme" quanto dal raggiungimento di un certo rango sociale, e quella che aleggia in Moderato cantabile, dove il bacio tra Anne e Chauvin, costruito in contrapposizione con la scena che apre il romanzo, pone la donna in una posizione esistenziale che lo studioso definisce "inhumaine": «Elle ne laisse que le choix entre la mort physique et la mort psychique».

7 Osserviamo infine che l'attenzione che l'autore dedica al contesto storico, sociale, culturale in cui ogni testo si inserisce (significativa, in questo senso, appare la riflessione sugli echi bellici che accomunano Mrs Dalloway e Il grande Gatsby, e che si traducono nei due testi in esperienze umane e letterarie molto diverse) arricchisce l'argomentazione senza mai - coerentemente con le premesse metodologiche imbrigliare l'analisi in nessi causali troppo rigidi.

8 In conclusione, Sept baisiers si presenta come un'opera allo stesso tempo unitaria e composita, capace non solo di parlare al mondo accademico e letterario, ma anche di rivolgersi a un pubblico ampio, purché colto abbastanza da seguire l'autore nel dedalo di riferimenti letterari, artistici, musicali che prende forma di pagina in pagina. 